\title{
NEBYLIOJO MIOKARDO INFARKTO APIBRËŽIMAS, RIZIKOS VEIKSNIAI IR RYŠYS SU STAIGIA MIRTIMI
}

\author{
Šarūnė Maksvytyte் ${ }^{1}$, Pranas Šerpytis ${ }^{1,2}$ \\ ${ }^{l}$ Vilniaus universiteto Medicinos fakultetas, ${ }^{2}$ Vilniaus universiteto ligonine Santaros klinikos
}

Raktažodžiai: nebylusis miokardo infarktas, apibrěžimas, simptomai, paplitimas, staigi mirtis, rizikos veiksniai.

\section{Santrauka}

Nebylusis miokardo infarktas (dar vadinamas besimptomis, tylusis, neatpažintas ar beskausmis MI) - tai simptomų nesukeliantis ar netipiškais simptomais pasireiškiantis miokardo infarktas, sudarantis daugiau nei pusę visų miokardo infarkto atvejų. Nepaisant augančio tyrimų, nagrinejjančių besimptomį miokardo infarktą patyrusių pacientų išgyvenamumo prognozę, skaičiaus, šios būklès ryšys su staigia mirtimi kol kas ištyrinètas nepakankamai, nedaug žinoma ir apie besimptomio miokardo infarkto paplitimą tarp tam tikrų pacientu grupių. Šiame straipsnyje nagrinejjamas nebyliojo miokardo infarkto apibrèžimas, su šia būkle susiję klinikiniai požymiai, rizikos veiksniai, analizuojama literatūra, aprašanti besimptomio miokardo infarkto ryši su staigia mirtimi. Literatūros apžvalgai naudoti 2015-2021 m. straipsniai. Remiantis atlikta apžvalga, pastebèta: nebylusis miokardo infarktas ịvairiuose literatūros šaltiniuose apibrèžiamas nevienareikšmiškai, kaip pagrindinị nebyliojo miokardo infarkto požymį išskiriant simptomų nebuvimą ar jų netipišką pasireiškimą; besimptomis miokardo infarktas reikšmingai didina staigios mirties riziką; jaunesnis amžius, vyriškoji lytis bei baltoji rasè tarp nebyliuoju miokardo infarktu sergančių asmenų susiję su didesne staigios mirties rizika; vyresnis amžius, hipertenzija, nutukimas, dislipidemija, cukrinis diabetas, autoimuninès ligos, perioperacinis laikotarpis yra galimi nebyliojo miokardo infarkto rizikos veiksniai.

\section{İvadas}

Nebylusis miokardo infarktas - tai simptomu nesukeliantis ar netipiškais simptomais pasireiškiantis miokardo infarktas. Šios būklès paplitimas įvairių tyrimų duomenimis gali siekti net iki 60 procentų. Nepaisant augančio tyrimų, nagrinejjančių besimptomį miokardo infarktą patyrusių paci- entų išgyvenamumo prognozę, skaičiaus, šios būklès ryšys su staigia mirtimi kol kas ištyrinètas nepakankamai. Šioje literatūros apžvalgoje plačiau panagrinèsime nebyliojo miokardo infarkto apibrèžimą, jam būdingus klinikinius požymius, besimptomio miokardo infarkto rizikos veiksnius bei šios būklès ryšị su staigia mirtimi.

Tyrimo tikslas - atlikti ne vèliau nei prieš $6 \mathrm{~m}$. publikuotų mokslinių straipsnių, nagrinèjančių su nebyliuoju miokardo infarktu susijusius klinikinius simptomus, nebyliojo miokardo infarkto paplitimą, rizikos veiksnius bei ryši su staigia mirtimi, analizę.

\section{Tyrimo objektas ir metodika}

Duomenys buvo renkami PubMed duomenų bazèje, taikyta Microsoft Academic žiniatinklių paieškos sistema. Analizei naudoti visateksčiai straipsniai, kurių pavadinimas, santrauka ir raktažodžiai atitiko apžvalgos tikslą. Analizuotos anglų kalba skelbtos 2015-2021 m. publikacijos. Literatūros apžvalgai atrinkti 33 straipsniai.

\section{Tyrimo rezultatai}

Nebyliojo miokardo infarkto apibrèžimas ir klinikiniai simptomai. Nebylusis miokardo infarktas (NMI) kai kuriuose šaltiniuose įvardijamas kaip besimptomis, tylusis, neatpažintas ar beskausmis MI (angl. asymptomatic, silent, unrecognized, painless myocardial infarction), literatūroje apibrèžiamas kaip simptomų nesukeliantis ar netipiniais simptomais pasireiškiantis negrịžtamas širdies raumens pažeidimas.

Remiantis 2018 m. Europos širdies asociacijos ketvirtuoju universaliu miokardo infarkto apibrèžimu (angl. Fourth universal definition of myocardial infarcion) [1], nebyliajam (neatpažintam) ar buvusiam MI būtinas bent vienas iš šių diagnostiniu kriterijų: 1) elektrokardiogramoje stebimos susiformavusios patologinès Q bangos, nesant kairiojo skilvelio hipertrofijos ar kairiosios Hiso pluošto kojytės blokados požymių pacientams su simptomais arba be jų ir nèra jokios žinomos neišeminès kilmès priežasties; 2) diagnostiniuose 


\section{6}

vaizdo tyrimuose stebimas išeminès priežasties sukeltas gyvybingo miokardo praradimas (vainikinès arterijos maitinimo zonoje sutrikusi miokardo kontrakcija ar nenormalus miokardo sienelès sustorejjimas arba suplonejjimas), tiesiogiai nesusijęs su trumpalaikès koronarinès revaskuliarizacijos procedūra ar atvykimu ị ligoninę dèl ūmaus koronarinio sindromo; 3) patologiniai radiniai, rodantys seniau ịvykusį MI. Klinikineje MI klasifikacijoje NMI išskiriamas iš kitų tipų. $\breve{S}$ i liga diferencijuotina su besimptome miokardo išemija - būkle, nepasireiškiančia krūtinès anginos simptomais ir lydima laikinų ST segmento pokyčiu elektrokardiogramoje, grižtamų regioninių miokardo sienelès kontrakcijos sutrikimų ar sutrikusios perfuzijos, stebimos scintigrafijoje [2].

Europos širdies asociacijos definicijoje išskirti kriterijai netiesiogiai nurodo, kad NMI nẻra būklè, reikalaujanti skubios kardiologinès intervencijos; tai patvirtina dauguma tyrimų, rodančių, jog minèta patologija dažniau susijusi su mažesniu nei kliniškai atpažintu MI širdies raumens pažeidimo plotu [3]. Kita vertus, kai kurie autoriai NMI išskiria tik kaip patologiją, susijusią su netipiškais simptomais ar jų nebuvimu (akcentuojant vẻlyvą kreipimąsi ị gydymo ịstaigas, pavėluotą diagnostiką bei gydymą), tačiau nekoreliuojančią su miokardo pažeidimo plotu [4-7].

Literatūroje pateikiama netipiško MI skausmo definicija nèra pakankamai tiksli. Kai kurie autoriai necharakteringiems MI požymiams priskiria šiuos simptomus: 1) mažesnio intensyvumo tipinius krūtinès anginos skausmus - diskomfortą krūtinès, rankos, apatinio žandikaulio srityse [8]; 2) klinikinius simptomus, pasireiškiančius neịprastinèse MI vietose - skausmą nugaros ar epigastriumo srityje, panašų ị nevirškinimo jausmą arba apibūdinamą kaip duriantị ar deginanti [9]; kaip nespecifiški simptomai ịvardinami ir su krūtinès skausmu nesusiję požymiai, tokie kaip tachikardija, palpitacijos, diaforezė, ryškus nuovargis ar dusulys [5-7, 10]. Kaip jau aptarta, nors didžioji dalis NMI atvejų nèra mirtini, simptomų išraiškingumas ne visada koreliuoja su pažeidimo plotu, todèl skubiosios pagalbos skyriuose ypač aukštos rizikos pacientams, atvykusiems su netipiniais simptomais, kliniškai visada turètų būti įtariama MI diagnozė. Šios būklès itraukimas ị diferencinę diagnozę ypač svarbus COVID-19 laikotarpiu, kai dalis ị prièmimo skyrius atvykusių pacientų skundžiasi tokiais nespecifiniais simptomais kaip dusuliu [7].

Nebyliojo miokardo infarkto paplitimas ir ryšys su staigios mirties rizika. Ivvairių tyrimų duomenimis, NMI sudaro apie 4-60 proc. visų MI atvejų [11-14], priklausomai nuo įtraukimo ị studijas kriterijų (amžius, lytis, rasė), NMI diagnostikai taikytų metodų (EKG, širdies echoskopija, širdies MRT) bei lyčiai specifiškų kriterijų (troponino vertės) (ne)taikymo. Tyrimai rodo, kad besimptomis MI susijęs su didesne kardiovaskulinių ligų, tarp jų ir pakartotinio infarkto, širdies nepakankamumo, išeminio insulto rizika bei didesniu bendruoju mirtingumu [11, 15-18], tačiau kol kas nedaug žinoma apie šios ligos ryši su staigia mirtimi.

Yun-Jiu Cheng ir kt. atliktoje studijoje [11] nagrinètos dvi didelès apimties ARIC (13 725 tiriamujų, 45-64 m.) ir CHS (5207 tiriamujų, $65 \mathrm{~m}$. ir vyresni) pacientų kohortos. Tyrimo rezultatai parode, kad NMI susijęs su 3 kartus didesne ilgalaike staigios mirties rizika, tačiau tarp tiriamujų, kuriems anksčiau buvo diagnozuotas tipiniais simptomais pasireiškęs MI, staigios mirties pasireiškimo dažnis buvo dar didesnis. Galima hipotetizuoti, kad blankesni simptomai ar jų nebuvimas NMI atveju būtent šioje tiriamujų grupèje buvo susiję su mažesniu širdies raumens pažeidimo plotu, o tai sietina su mažesne piktybinių aritmijų išsivystymo, todèl ir staigios mirties rizika. Atkreiptinas dèmesys ị keletą su studija susijusių aspektų, galimai turejusių itakos nevisiškai tiksliam staigios mirties rizikos įvertinimui tiriamojoje populiacijoje. Minètame tyrime besimptomio MI diagnostika nesant klinikinių simptomų ar jų netipiškumo, rėmėsi vien elektrokardiografiniais NMI požymiais. EKG nèra jautrus ir specifiškas diagnostikos metodas, elektrokardiografiniai MI požymiai laikui bėgant gali išnykti, nulemdami NMI paplitimo bei staigios mirties rizikos tarp NMI sergančių asmenų vertinimo nuokrypius. Jeigu NMI apibrèžtume remdamiesi vien simptomų netipiškumu ar jų nebuvimu, galètume stebèti, kad tyrime (kaip ir žemiau aptariamuose) analizuota ilgalaike staigios mirties rizika, i jị neịtraukti pacientai, i ligoninę atvykę su netipiniais simptomais, tačiau didelio ploto miokardo pažeidimu, reikalingu skubios kardiologinès intervencijos. Simptomų, ypač skausmo, nebuvimas pavèlina kreipimąsi ị gydymo ịstaigas, sunkina MI diagnostiką, prailgina laiką iki reperfuzinės terapijos pradžios (ang1. door-to-balloon time) [4], todèl labai tikètina, kad tokiose situacijose NMI būtų susijęs su dar didesne staigios mirties rizika, nei tipinis MI.

Minètoje studijoje stebèta ryški koreliacija tarp NMI paplitimo ir vyresnio (ypač $>65 \mathrm{~m}$.) amžiaus, vyriškosios lyties bei žemesnio išsilavinimo. Kai kurie tyrimai parode, kad besimptomis MI buvo dažnesnis žemesnio socioekonominio sluoksnio tiriamiesiems [19]. Pacientų, patyrusių besimptomi MI, lyginant su nesirgusiais MI, anamnezèje dažniau buvo didesnis kūno masès indeksas (KMI), hipertenzija, cukrinis diabetas, tačiau rūkymo ir alkoholio vartojimo paplitimas NMI grupejje buvo mažesnis.

Nors NMI dažnis buvo didesnis tarp vyresnio amžiaus asmenų, turinčių daugiau kardiovaskulinès rizikos veiksnių, tyrime didžiausia staigios mirties rizika stebeta jaunesniems pacientams ir tiems, kurie be minèto amžiaus kriterijaus, buvo baltaodžiai, dažniau - vyrai. Tyrimo rezultatai parodè, kad jaunus pacientus didžioji dalis staigios mirties atvejų 
ištikdavo fizinio krūvio metu ar lauke. Nepriklausydami standartinei kardiovaskulinès rizikos grupei, jauni pacientai rečiau lankosi gydymo ịstaigose, todèl galima daryti prielaidą, kad neturèdami pakankamai informacijos apie savo sveikatos būklę, neriboja su didesne piktybinių aritmijų išsivystymo rizika susijusios fizinès veiklos. Manoma, jog vyrai geriau toleruoja skausmą nei moterys, todèl galimai rečiau kreipiasi i asmens sveikatos priežiūros įstaigas ir pradedami gydyti pavèluotai; minètam rizikos pasiskirstymui tarp baltaodžių ir vyrų galimai įtakos turi ir genetiniai veiksniai.

Juha H. Vähätalo ir kt. atvejo kontrolès studijos [20], i kurią įtraukti 4392 tiriamieji (amžiaus vidurkis 66,2 m.), mirę dèl staigaus išeminès kilmès širdies pažeidimo, rezultatai parodè, kad beveik trys ketvirtadaliai pacientų prieš mirtị neturejo diagnozuotos koronarinès širdies ligos, iš jų apie 40 proc. širdies raumens histologinèje medžiagoje buvo stebimas senas randas, rodantis nediagnozuotą MI. Kaip ir aptartame tyrime, šioje studijoje didesnis NMI paplitimas koreliavo su vyresniu amžiumi ir vyriška lytimi. Su besimptomiu MI susijusi mirtis dažniau ịvykdavo fizinio krūvio metu.

FinGesture studijoje [21] analizuotas autopsijos būdu verifikuoto NMI paplitimas tarp jaunų ( $<50 \mathrm{~m}$.) asmenų, nesirgusių diagnozuota koronarine širdies liga, ištiktų staigios širdinès kilmès mirties. 10 proc. staigios mirties atvejų buvo susiję su jaunesniais nei $50 \mathrm{~m}$. žmonèmis, dažniausia jos priežastis $(44 \%)$ - koronariné širdies liga, kuri aptartoje tiriamujų grupeje 90 proc. atvejų nebuvo diagnozuota anksčiau. Trečdaliui (34 \%) tiriamųjų, neturejjusių koronarinès širdies ligos diagnozės, atliekant autopsiją stebèti dèl NMI susiformavę randai. Kaip ir jau anksčiau aptartose studijose, didžiają dali ( $87 \%$ ) jaunesnių nei $50 \mathrm{~m}$. staigios mirties aukų sudarė vyrai, didesnis jų staigios mirties dažnis dažniau buvo siejamas su fizine veikla. Širdies hipertrofija ir trijų vainikinių arterijų liga buvo identifikuotos dviems trečdaliams tiriamujjų, apie penktadaliui iš jų nustatyta padidejusi alkoholio koncentracija kraujyje. Šie radiniai leidžia teigti, kad NMI yra nereta patologija ne tik vyresniame, bet ir jauname amžiuje. Atlikus tyrimą pastebèta, kad per 20 metu su koronarine širdies liga susijusiu mirčiu skaičius šioje populiacijoje sumažèjo nuo 50 ir 35 proc. dèl galimai efektyvesnio prevencinių programų veikimo.

\section{Besimptomio miokardo infarkto rizikos veiksniai}

Lytis. Literatūroje pateikiami duomenys, kuriuose nagrinejjamas NMI paplitimas tarp skirtingos lyties asmenų, nėra vienareikšmiški. Pin Pin Pek ir kt. 2016 m. atliktame retrospektyviniame tyrime [4], ị kurị itraukti 6412 pacientų, esant ūmiam ST pakilimo MI, parode, kad NMI dažesnis moterims. Andrea Milde Øhrn ir kt. 2016 m. atlikta skers- pjūvio studija [22] su 4849 tiriamaisiais parodè, kad MI dažniau buvo neatpažintas moterims, nei vyrams. Remiantis 2019-2021 m. duomenimis iš jau aptartų didelès apimties kohortinių ir atvejo kontrolès tyrimų [11,15,21], NMI dažnesnis vyrams, o staigios mirties rizika didesnè jaunesnių vyrų populiacijoje ir dažniausiai siejama su fizinio krūvio išprovokuota išemija.

Rase. Yun-Jiu Cheng ir kt. studijoje [11] stebetas didesnis NMI paplitimas baltosios rasės asmenims, tačiau kol kas trūksta tyrimų, kuriuose būtų lyginamas NMI pasireiškimo dažnis tarp visų rasių.

Vyresnis amžius ir tradiciniai (Framingham) kardiovaskulinès rizikos veiksniai. Daugelyje tyrimų stebima koreliacija tarp vyresnio amžiaus ir didesnio NMI paplitimo $[11,15,21]$. Galimai tai susiję su dažnesniu pagrindinių rizikos veiksnių pasireiškimu vyresnio amžiaus populiacijoje (dislipidemija, hipertenzija, cukrinis diabetas, nutukimas, ilga rūkymo trukmè), kurie didina besimptomio ir simptominio MI riziką [23].

Cukrinis diabetas. Cukrinis diabetas (CD) susijęs su dviem-keturiais kartais didesne kardiovaskulinių ịvykių rizika [24]. Manoma, kad didesnis besimptomio MI paplitimas $\mathrm{CD}$ ar netgi prediabetu sergančių pacientų populiacijoje yra susijęs su dažnesniu širdies autonominès neuropatijos (ŠAN) pasireiškimu [25]. ŠAN dažnis tiesiogiai koreliuoja su CD trukme, glikemijos kontrole, cukrinio diabeto sukeltomis mikrovaskulinemis komplikacijomis (nefropatija, retinopatija, periferiné neuropatija). Manoma, kad minètos patologijos atsiradimui itakos turi tokie kardiovaskuliniai rizikos veiksniai kaip arterinė hipertenzija, didelè trigliceridų (TAG), MTL, sumažejjusi DTL koncentracija kraujyje, padidèjęs kūno masès indeksas (2 tipo cukrinio diabeto atveju) bei rūkymas [26]. ŠAN vystymasis siejamas su hiperglikemijos sukeltu toksinių glikozilinimo produktų susidarymu ir padidejusia reaktyviujų deguonies formų gamyba mitochondrijose [27]. Yra duomenų, kad ŠAN galimai įtakos turi ne tik nuolatinè hiperglikemija, bet ir dideli gliukozės koncentracijos kraujyje svyravimai. [28] Oksidacinis stresas mažina neurosiuntiklių išsiskyrimą iš sinapsès, sukelia sinapsės disfunkciją, slopina neuronų regeneraciją bei aktyvina apoptozès procesus nerviniame audinyje. ŠAN pradžia siejama su nervo klajoklio (n. vagus) pažeidimu [27]. Dèl šios sistemos pakenkimo padidèjęs simpatinès nervų sistemos tonusas sukelia dažnesnị ramybès tachikardijos, ortostatinès hipotenzijos pasireiškimą. Vèlesnèse ŠAN stadijose pažeidžiama simpatinè nervų sistema. Kadangi autonominè nervų sistema dalyvauja su MI susijusių simptomų formavimesi, minètas denervacijos procesas galimai paaiškina sergančiųų CD besimptomio MI kliniką. Be hiperglikemijos, žinomos ir kitos ŠAN CD sergantiems asmenims predisponuojančios priežastys, ịskai- 


\section{8}

tant genetines, autoimunines ir infekcines. Šios patologijos vystymuisi galimai įtakos turi ir didesnis obstrukcinès miego apnejos paplitimas tarp CD sergančių asmenų [29].

Autoimuniness ligos. Autoimuninèmis reumatologinèmis ligomis sergančių pacientų populiacijoje kardiovaskulinis sergamumas ir mirštamumas didesni nei bendrojoje, tačiau ryšys tarp autoimuninių širdies ligų ir besimptomio MI paplitimo nèra pakankamai ištirtas [30]. Literatūroje daugiausia duomenu pateikiama apie nagrinejjamos būklès sąsają su reumatoidiniu artritu (RA). Kai kurie epidemiologiniai tyrimai rodo, kad besimptomès išeminès širdies ligos, taip pat ir besimptomio MI bei staigios mirties rizika tarp RA sergančiu asmenų yra didesnè, nei bendrojoje populiacijoje [31]. Patofiziologiniai NMI išsivystymo mechanizmai šioje populiacijoje kol kas nèra galutinai išaiškinti. Didesnis besimptomio MI paplitimas tarp RA sergančių asmenų galimai susijęs šios ligos sukeliamu lètiniu sisteminiu uždegimu, skatinančiu greitesnị aterosklerozės progresavimą [6]. Ivairių tyrimų duomenimis, 24-100 proc. reumatoidiniu artritu sergančių pacientų turi ŠAN, kuri, kaip hipotetizuojama, RA atveju susijusi su lètinio uždegimo sukeltu neurotoksiniu poveikiu [6]. Uždegiminis procesas stebimas visų autoimuninių reumatinių ligų atvejais, tad galimai minèti greičiau progresuojančios aterosklerozès bei ŠAN vystymosi mechanizmai galètų paaiškinti ir kitų reumatologinių ligų ir dažnesnio širdies pažeidimo sąsają.

Perioperacinis laikotarpis. Remiantis kai kurių tyrimų duomenimis, NMI sudaro nemažą dalį visų MI, i̇vykusių ne širdies operacijų perioperaciniu laikotarpiu. POISE-1 kohortinės studijos, ị kurią įtraukti 8351 pacientai, rezultatai parodé, kad iš 5 proc. tiriamuju, kuriems perioperaciniu laikotarpiu diagnozuotas MI, net 65 proc. po operacijos nesiskundè jokiais išeminiais simptomais [32]. Christian Puelacher ir kt. atliktoje prospektyvinèje diagnostinèje studijoje [33], apėmusioje 2546 pacientus (amžiaus vidurkis - 74 m., $42 \%$ tiriamujų sudaré moterys), stebèta, kad tik 6 proc. pacientų, kuriems diagnozuotas perioperacinis MI, jaute tipinius krūtinès skausmus. Šiuos statistinius rezultatus galejo nulemti tokie kintamieji kaip tyrimuose dalyvavusių pacientu vyresnis amžius, gretutiniu ligu (hipertenzijos, cukrinio diabeto ir kt.) buvimas, operacijos pobūdis bei ilgesnè jos trukmè, susijusi su didesnių analgetikų ir sedacinių vaistų dozių skyrimu ir ilgesniu šių vaistų pooperaciniu efektu. Kadangi besimptomis MI susijęs su didesne mirštamumo ir kartotinių didžiujų kardiovaskulinių komplikacijų rizika, pagrindinių rizikos grupių asmenų (kai kuriuose tyrimuose kaip pagrindiniai perioperacinio MI rizikos veiksniai identifikuoti rūkymas, hipertenzija ir cukrinis diabetas) identifikavimas ir šių asmenų pooperacinès troponino koncentracijos kraujyje stebejimas yra svarbūs ankstyvosios NMI diagnostikos elementai [32].

\section{Išvados}

1. Skirtinguose literatūros šaltiniuose besimptomis miokardo infarktas apibrěžiamas nevienareikšmiškai, tačiau kaip pagrindinis skiriamasis nebyliojo miokardo infarkto bruožas įvardijamas simptomų nebuvimas arba jų netipiškumas.

2. Nebylusis miokardo infarktas sudaro didžiają dali visų miokardo infarktų ir yra susijęs su 3 kartus didesne ilgalaike staigios mirties rizika.

3. Jaunesnis amžius, vyriškoji lytis ir baltoji rasė tarp besimptomiu miokardo infarktu sergančių asmenų susiję su didesne staigios mirties rizika.

4. Vyresnis amžius, hipertenzija, nutukimas, dislipidemija, cukrinis diabetas, autoimuninès ligos, perioperacinis laikotarpis priskiriami besimptomio miokardo infarkto rizikos veiksniams.

\section{Literatūra}

1. Thygesen K, Alpert JS, Jaffe AS, Chaitman BR, Bax JJ, Morrow DA, et al. Fourth universal definition of myocardial infarction. J Am Coll Cardiol 2018;72(18):2231-64. https://doi.org/10.1016/j.jacc.2018.08.1038

2. Gul Z, Makaryus AN. Silent myocardial ischemia. In: StatPearls 2021. http://www.ncbi.nlm.nih.gov/books/NBK536915/

3. Manolis AS. Editorial commentary: prior silent/unrecognized myocardial infarction and heart failure: size/extent matters. Trends Cardiovasc Med 2019;29(4):245-7.

https://doi.org/10.1016/j.tcm.2018.09.006

4. Pek PP, Loy EY, Wah W, Ho AFW, Zheng H, Fook-Chong SMC, et al. Reperfusion treatment delays amongst patients with painless ST segment elevation myocardial infarction. Can J Emerg Med 2017;19(5):355-63.

https://doi.org/10.1017/cem.2016.376

5. Prochnau D, Glück G, Holz I, Lascho C, Eggers R. Painless myocardial infarction - a clinical challenge in the emergency department. Can J Emerg Med 2019;21(4):557-9.

https://doi.org/10.1017/cem.2019.11

6. Unnikrishnan D, Jacob A, Diaz MA, Lederman J. Silent myocardial infarction secondary to cardiac autonomic neuropathy in a patient with rheumatoid arthritis. Case Rep 2016:bcr2016215257.

https://doi.org/10.1136/bcr-2016-215257

7. Tschöpe C, Sherif M, Anker MS, Geisel D, Kuehne T, Kelle S. COVID-19-convalescence phase unmasks a silent myocardial infarction due to coronary plaque rupture. ESC Heart Fail 2021;8(2):971-3.

https://doi.org/10.1002/ehf2.13186

8. Aghdam MRF, Vodovnik A, Sund BS. Sudden death associated with silent myocardial infarction in a 35-year-old man: a case report. J Med Case Reports 2016;10(1):46.

https://doi.org/10.1186/s13256-016-0823-9

9. DeVon HA, Mirzaei S, Zègre-Hemsey J.Typical and atypical 
symptoms of acute coronary syndrome: time to retire the terms? J Am Heart Assoc 2020;9(7):e015539.

https://doi.org/10.1161/JAHA.119.015539

10. Tasaki T, Yamada S, Nabeshima A, Noguchi H, Nawata A, Hisaoka M, et al. An autopsy case of myocardial infarction due to idiopathic thrombotic thrombocytopenic purpura. Diagn Pathol 2015;10(1):52.

https://doi.org/10.1186/s13000-015-0285-1

11. Cheng Y-J, Jia Y-H, Yao FJ, et al. Association between silent myocardial infarction and long-term risk of sudden cardiac death. J Am Heart Assoc 2021;10(1):e017044.

https://doi.org/10.1161/JAHA.120.017044

12. Turkbey EB, Nacif MS, Guo M, McClelland RL, Teixeira PBRP, Bild DE, et al. Prevalence and correlates of myocardial scar in a US cohort. JAMA 2015;314(18):1945.

https://doi.org/10.1001/jama.2015.14849

13. Soliman EZ. Silent myocardial infarction and risk of heart failure: current evidence and gaps in knowledge. Trends Cardiovasc Med 2019;29(4):239-44.

https://doi.org/10.1016/j.tcm.2018.09.004

14. Amier RP, Smulders MW, Bekkers SCAM, Roos ST, Teunissen PFA, Appelman YEA, et al. 294 long-term prognosis of silent myocardial infarction detected by LGE-CMR in patients presenting with first acute myocardial infarction. Eur Heart J 2017;38(ehx501.294).

https://doi.org/10.1093/eurheartj/ehx501.294

15. Vähätalo JH, Huikuri HV, Holmström LTA, Kenttä TV, Haukilahti MAE, Pakanen L, et al. Association of silent myocardial infarction and sudden cardiac death. JAMA Cardiol 2019;4(8):796-802.

https://doi.org/10.1001/jamacardio.2019.2210

16. Zhang Z-M, Rautaharju PM, Prineas RJ, et al. Race and sex differences in the incidence and prognostic significance of silent myocardial infarction in the atherosclerosis risk in communities (ARIC) study. Circulation 2016;133(22):2141-8. https://doi.org/10.1161/CIRCULATIONAHA.115.021177

17. Valensi P, Meune C. Congestive heart failure caused by silent ischemia and silent myocardial infarction. Herz 2019;44(3):2107.

https://doi.org/10.1007/s00059-019-4798-3

18. Merkler AE, Bartz T, Kamel H, et al. Abstract 58: silent myocardial infarction and subsequent ischemic stroke in the cardiovascular health study. Stroke 2021;52(Suppl_1):A58. https://doi.org/10.1161/str.52.suppl_1.58

19. Patel N, Ahmad MI, Zhang W, Soliman EZ. Interrelations of cumulative social risk, silent myocardial infarction, and mortality in the general population. Am J Cardiol 2020;125(12):1823-8. https://doi.org/10.1016/j.amjcard.2020.03.026

20. Vähätalo JH, Huikuri HV, Holmström LTA, Kenttä TV, Haukilahti MAE, Pakanen L, et al. Association of silent myocardial infarction and sudden cardiac death. JAMA Cardiol
2019;4(8):796-802.

https://doi.org/10.1001/jamacardio.2019.2210

21. Vähätalo J, Holmström L, Pakanen L, Kaikkonen K, Perkiömäki $\mathrm{J}$, Huikuri $\mathrm{H}$, et al. Coronary artery disease as the cause of sudden cardiac death among victims $<50$ years of age. Am J Cardiol 2021;147:33-38.

https://doi.org/10.1016/j.amjcard.2021.02.012

22. Øhrn AM, Nielsen CS, Schirmer H, Stubhaug A, Wilsgaard T, Lindekleiv H. Pain tolerance in persons with recognized and unrecognized myocardial infarction: a population-based, cross-sectional study. J Am Heart Assoc 2016;5(12):e003846. https://doi.org/10.1161/JAHA.116.003846

23. Williams SM, Eleftheriadou A, Alam U, Cuthbertson DJ, Wilding JPH. Cardiac autonomic neuropathy in obesity, the metabolic syndrome and prediabetes: a narrative review. Diabetes Ther 2019;10(6):1995-2021.

https://doi.org/10.1007/s13300-019-00693-0

24. Singleton MJ, German CA, Bertoni AG, et al. Association of silent myocardial infarction with major cardiovascular events in diabetes: the ACCORD trial. Diabetes Care 2020; 43(4): e45-e46 https://doi.org/10.2337/dc19-2201

25. Ziegler D, Voss A, Rathmann W, Strom A, Perz S, Roden M, et al. Increased prevalence of cardiac autonomic dysfunction at different degrees of glucose intolerance in the general population: the KORA S4 survey. Diabetologia 2015;58(5):1118-28. https://doi.org/10.1007/s00125-015-3534-7

26. Serhiyenko VA, Serhiyenko AA. Cardiac autonomic neuropathy: risk factors, diagnosis and treatment. World J Diabetes 2018;9(1):1-24.

https://doi.org/10.4239/wjd.v9.i1.1

27. Agashe S, Petak S. Cardiac autonomic neuropathy in diabetes mellitus. Methodist Debakey Cardiovasc J 2018;14(4):251-6.

28. Bissinger A. Cardiac autonomic neuropathy: why should cardiologists care about that? J Diabetes Res 2017; 2017: 5374176. https://doi.org/10.1155/2017/5374176

29. Fisher VL, Tahrani AA. Cardiac autonomic neuropathy in patients with diabetes mellitus: current perspectives. Diabetes Metab Syndr Obes Targets Ther 2017;10:419-34. https://doi.org/10.2147/DMSO.S129797

30. Amaya-Amaya J, Montoya-Sánchez L, Rojas-Villarraga A. Cardiovascular involvement in autoimmune diseases. BioMed Research International 2014; Article ID 367359.

ttps:// hdoi.org/10.1155/2014/367359

31. DeMizio DJ, Geraldino-Pardilla LB. Autoimmunity and inflammation link to cardiovascular disease risk in rheumatoid arthritis. Rheumatology and Therapy 2020;7:19-33.

https://doi.org/10.1007/s40744-019-00189-0

32. Borges FK, Devereaux PJ. The silent burden of perioperative myocardial infarction after noncardiac surgery. Can J Cardiol 2021;37(2):188-90. 
https://doi.org/10.1016/j.cjca.2020.06.007

33. Puelacher C, Buse GL, Seeberger D, Sazgary L, Marbot S, Lampart A, et al. Perioperative myocardial injury after noncardiac surgery: incidence, mortality, and characterization. Circulation 2018;137(12):1221-32.

https://doi.org/10.1161/CIRCULATIONAHA.117.030114

\section{SILENT MYOCARDIAL INFARCTION: DEFINITION, RISK FACTORS AND ASSOCIATION WITH SUDDEN CARDIAC DEATH}

\section{Š. Maksvytytė, P. Šerpytis}

Keywords: silent myocardial infarction, definition, symptoms, prevalence, sudden cardiac death, risk factors.

Summary

Silent myocardial infarction (also defined as asymptomatic, unrecognized, or painless MI) is described as myocardial infarction with atypical clinical presentation or without any symptoms. Silent myocardial infarctions make more than half of all myocardial infarctions. Despite the growing number of studies analysing prognosis of this condition not much is known about the relationship between unrecognized myocardial infarction and sudden cardiac death. In this article we will review definition of silent myocardial infarction, clinical symptoms and risk factors related to this condition as well as its connection with sudden cardiac death. The articles from 2015 to 2021 were used for the literature review. Based on this review, it was observed that there is some inconsistency among different authors regarding the definition of silent myocardial infarction and as the main common distinguishing feature of this condition the absence of symptoms or atypical manifestations are described; younger age, male sex and whites are the main risk factors of sudden cardiac death between patients having silent myocardial infarction; older age, hypertension, obesity, dyslipidemia, diabetes mellitus, autoimmune diseases and perioperative period are or may be the risk factors for the highest prevalence of silent myocardial infarction.

Correspondence to: sarune25@gmail.com

Gauta 2021-04-22 